\title{
Penilaian Kelayakan Peminjaman pada Usaha Kecil Menengah Koperasi Menggunakan Metode Fuzzy Tsukamoto
}

\section{(Feasibility Assessment of Small Medium Enterprises Using Fuzzy Tsukamoto Method in Koperasi Pasar Manis Purwokerto)}

\author{
Hindayati Mustafidah ${ }^{1)}$ dan Akbar Wiraisy ${ }^{2)}$ \\ ${ }^{1,2}$ Teknik Informatika - F. Teknik dan Sains - Universitas Muhammadiyah Purwokerto \\ Jl. Raya Dukuhwaluh Purwokerto 53182 \\ 1) fida.mustafidah@ump.ac.id \\ 2) wiraisy@gmail.com
}

\begin{abstract}
Abstrak - Dalam perekonomian Indonesia, sektor Usaha Kecil dan Menengah (UKM) memainkan peran yang sangat penting, terutama jika dikaitkan dengan jumlah tenaga kerja yang dapat diserap. Pertumbuhan UKM di Indonesia masih sangat bergantung pada masalah modal. Sebagai contoh kasus di "Koperasi Pasar Manis Sejahtera" di Purwokerto merupakan salah satu lembaga keuangan yang memiliki visi untuk meningkatkan pertumbuhan Usaha Kecil dan Menengah. Kebutuhan sistem untuk menilai kelayakan penerima pinjaman adalah persyaratan inti bahwa proses pembiayaan dapat berjalan dengan lancar. Kebutuhan akan sistem yang memiliki ketepatan dalam memberikan penilaian terhadap pengajuan pinjaman di Koperasi merupakan hal yang sangat penting. Untuk itu, dalam penelitian ini dikembangkan sistem berbasis inferensi fuzzy Tsukamoto dengan alasan bahwa beberapa variabel yang digunakan sebagai pertimbangan pengajuan pinjaman adalah bersifat fuzzy. Variabel yang digunakan sebagai input sistem adalah karakter, jaminan, kemampuan, dan usaha. Model Rapid Application Development (RAD) digunakan sebagai teknologi pengembangan system. Hasil penelitian menunjukkan bahwa sistem yang dibangun dapat membantu pengambil keputusan dalam menilai kelayakan calon penerima kredit di Koperasi khususnya Koperasi Pasar Manis Sejahtera Purwokerto.
\end{abstract}

Kata-kata kunci - sistem inferensi fuzzy, Tsukamoto, pinjaman, UKM, Koperasi.

Abstract -In the Indonesian economy, the Small and Medium Enterprises (SME) sector plays a very important role, especially if associated with the amount of labor that can be absorbed. The growth of SME in Indonesia is still very dependent on capital problems. For example, the case in the "Koperasi Pasar Manis Sejahtera" in Purwokerto is one of the financial institutions that have vision to increase the growth of Small and Medium Enterprises. The system needs to assess the eligibility of loan recipients is a core requirement that the financing process can run smoothly. The need for a system that has the accuracy in providing an assessment of loan applications in cooperatives is very important. For this reason, in this study developed a Tsukamoto fuzzy inference system based on the grounds that several variables used as a consideration for loan application are fuzzy. The variables used as system inputs are characters, guarantees, capabilities, and effort. Rapid Application Development (RAD) model is used as a system development technology. The results of the study indicate that the system built can help decision makers in assessing the feasibility of prospective recipients of credit in the Cooperative, especially the "Koperasi Pasar Manis Sejahtera " Purwokerto.

Keywords - fuzzy inference system, Tsukamoto, loan, SME, Cooperative.

\section{PENDAHULUAN}

Memulai ataupun menjalankan sebuah usaha tentunya akan mendapatkan berbagai macam kendala yang kompleks, diawali dengan kebutuhan untuk mendapatkan modal sampai dengan masalah operasional yang timbul saat usaha mulai berjalan. Pembayaran cicilan kredit usaha ditambah dengan bunga pinjaman dinilai memberatkan para pengusaha 
kecil diakibatkan tingkat suku bunga bank yang dinilai terlalu tinggi dan tidak sebanding dengan persentase pendapatan yang diperoleh. Hal ini disebabkan uji kelayakan dalam pemberian kredit sering kali tidak dilakukan sebagaimana mestinya. Selain itu, dalam melakukan proses pengambilan keputusan perbankan masih menggunakan teknik skoring. Penggunaan teknik skoring ini berakibat nilai tidak fleksibel, sehingga para pengusaha sulit untuk mencapainya karena berbagai keterbatasan yang dimilikinya. KOPAMAS (Koperasi Pasar Manis Sejahtera Purwokerto) merupakan salah satu lembaga keuangan yang memiliki visi untuk meningkatkan pertumbuhan Usaha Kecil Menengah. Perlunya sebuah sistem untuk melakukan penilaian kelayakan penerima pinjaman merupakan kebutuhan inti agar pembiayaan dapat berjalan dengan tepat guna. Sistem berbasis logika fuzzy dipilih dalam penelitian ini karena logika fuzzy merupakan suatu cara yang tepat untuk menghitung gradasi tak terbatas jumlahnya antara benar dan salah [1]. Logika Fuzzy merupakan proses pengembangan dari logika Boolean, yang digunakan untuk menangani konsep derajat kebenaran, yaitu nilai kebenaran antara benar dan salah. Teori ini diperkenalkan oleh Dr. Lotfi Zadeh dari Barkeley pada tahun 1960-an, sebagai model ketidakpastian. Logika fuzzy telah banyak dikembangkan dalam berbagai aplikasi baik di bidang ekonomi, otomotif, maupun pendidikan.

Pada bidang ekonomi, inferensi Sugeno dikembangkan oleh [2] untuk mengevaluasi resiko pemberian Kredit Usaha. Selain itu, metode fuzzy juga digunakan untuk memprediksi pemberian rating dalam menilai tingkat resiko pada jenis usaha pemberian kredit atau pinjaman usaha di CIB Egyptian Commercial Bank [3]. Metode Data Envelopment Analysisis (DEA) yang dikombinasikan dengan sistem Neuro Fuzzy dikembangkan oleh [4] untuk melakukan analisis terhadap keputusan dalam penentuan kelayakan kredit. Variabel masukan yang digunakan adalah ratarata dari total hutang, jumlah kredit, jumlah agunan, total nominal pembayaran, total nominal pendapatan, dan total jam kerja.

Sementara itu, di bidang otomotif logika fuzzy digunakan untuk membangun sebuah sistem pendukung keputusan untuk kustomisasi massal dengan luaran sistem berupa komponen otomotif yang sesuai [5]. Masukan sistem berupa kriteria kecepatan, bahan bakar ekonomis, jenis rem dan tingkat kecanggihan sistem pengereman. Di bidang pendidikan, logika fuzzy dikembangkan untuk memprediksi prestasi belajar mahasiswa [6], memprediksi tingkat kelulusan mahasiswa [7], penentuan tingkat kompetensi pendidik
[8] dan [9], untuk mengetahui korelasi tingkat kompetensi dosen terhadap tingkat kelulusan mahasiswa [10], dan untuk mengetahui pengaruh motivasi belajar dan lingkungan belajar terhadap prestasi belajar mahasiswa [11].

Berdasarkan uraian tersebut, maka dapat diduga bahwa sistem berbasis inferensi fuzzy dapat digunakan sebagai sistem yang berfungsi untuk memprediksi kelayakan pemberian pinjaman di Koperasi Pasar Manis Sejahtera Purwokerto. Harapan dengan adanya sistem ini, pengguna (pemberi keputusan peminjaman) lebih terbantu dan lebih mudah dalam melakukan penilaian terhadap kelayakan calon penerima pinjaman, sehingga mendapatkan kriteria calon yang sesuai untuk mendapatkan pencairan kredit usaha.

\section{METODE PENELITIAN}

Penelitian ini diawali dengan pengumpulan data menggunakan metode wawancara, observasi, dan dokumentasi. Sistem dibangun menggunakan bahasa pemrograman Java dengan keunggulannya berupa bahasa pemrograman yang portable karena dapat dijalankan pada berbagai sistem operasi dengan fitur $J V M$ [12]. Sistem inferensi fuzzy yang digunakan adalah Tsukamoto dengan langkah seperti pada Gambar 1 .

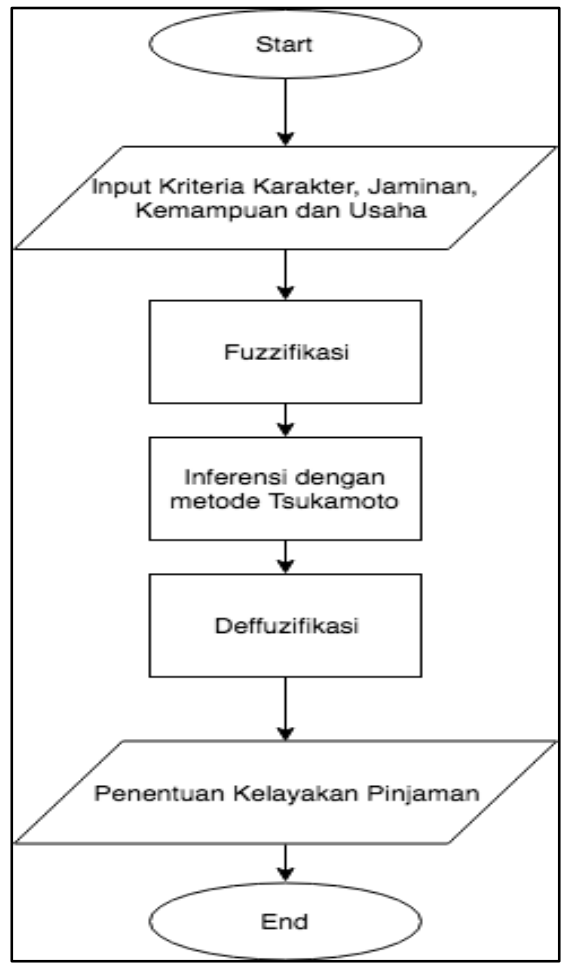

Gambar 1. Alur pengembangan sistem inferensi fuzzy Tsukamoto untuk menentukan kelayakan peminjaman 
Masukan sistem berupa nilai dari kriteria karakter, jaminan, kemampuan, dan usaha. Kriteria-kriteria ini bernilai crisp. Pada tahapan fuzzifikasi, dilakukan pembentukan himpunan fuzzy dan menentukan derajat keanggotaannya, serta mengaplikasikan fungsi implikasi metode Min. Selanjutnya dilakukan evaluasi pada setiap aturan (rule) yang telah dibangun sebelumnya menggunakan inferensi Tsukamoto. Defuzzifikasi dilakukan menggunakan metode Weighted Average (rata-rata terbobot) yang digunakan sebagai dasar dalam penentuan derajat keanggotaan pada himpunan penilaian kelayakan peminjaman.

\section{HASIL DAN PEMBAHASAN}

\section{A. Rancangan Sistem Fuzzy}

Pengembangan sistem pada penelitian ini digunakan model RAD (Rapid Application Development). Ilustrasi metode RAD (Rapid Application Development) menurut [13] dapat dilihat pada Gambar 2. Sesuai dengan langkah dalam RAD, pengembangan sistem dilakukan berdasarkan urutan: 1) mengidentifikasi tujuan dan syarat-syarat, 2) bekerja dengan pengguna untuk merancang sistem, 3) membangun sistem, dan 4) mengenalkan sistem baru.

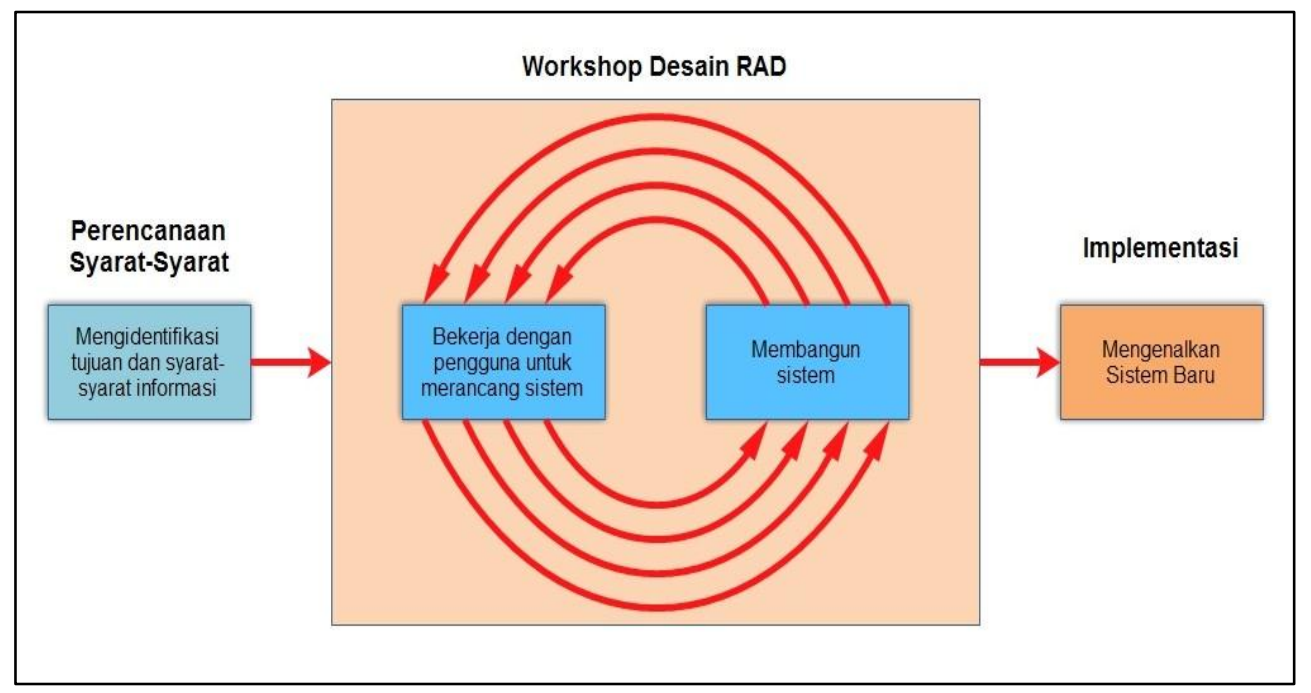

Gambar 2. Fase RAD (Rapid Application Development)

Mekanisme pemberian kredit atau pinjaman pada UKM di KOPAMAS Purwokerto diawali dengan permohonan pinjaman dari anggota koperasi dengan melengkapi persyaratan yang ada. Setelah berkas lengkap maka masuk ke dalam tahap wawancara. Sistem yang dibangun ini tidak menggantikan mekanisme pengajuan pinjaman yang telah ada, namun hanya memperbarui metode penilaian yang sebelumnya dari metode Scoring menjadi metode Fuzzy Tsukamoto.
Sistem fuzzy ini menggunakan variabel input berupa kriteria karakter, jaminan, kemampuan, dan usaha. Penggunaan kriteria dalam penelitian ini didasarkan pada perumusan konsep $5 \mathrm{C}$ dan $7 \mathrm{P}$ yang merupakan unsur-unsur dalam pemberian kredit [14]. Perhitungan nilai kriteria menggunakan teknik pembobotan Benefit dan Cost yang pada umumnya digunakan pada Sistem Pendukung Keputusan dengan metode SAW. Keterangan variabel input tersaji pada Tabel I.

TABEL I

VARIABEL INPUT KRITERIA

\begin{tabular}{llll}
\hline No & Kriteria & \multicolumn{1}{c}{ SubKriteria } & \multicolumn{1}{c}{ Perhitungan Nilai } \\
\hline 1 & Jaminan & Nilai Agunan & Taksiran Nilai Agunan \\
& & Nilai Rata - Rata Jaminan & Taksiran Nilai Agunan / Total Pinjaman \\
& \multirow{2}{*}{ Usaha } & Penggunaan modal pribadi $(\%)$ & Nilai Penggunaan Modal Pribadi / 10 \\
& & Keuntungan Usaha & Nilai keuntungan Usaha (0 - 10) \\
& & Lokasi usaha & Nilai Lokasi usaha $(0-10)$ \\
& & Tingkat Persaingan Usaha & 10 / Nilai Persaingan Usaha \\
& & Jumlah Tenaga kerja & Jumlah Tenaga kerja (1 - 10) \\
& Nilai Rata- Rata Usaha & Total Nilai Usaha/ 5 \\
\hline
\end{tabular}




\begin{tabular}{|c|c|c|c|}
\hline \multirow[t]{4}{*}{4} & Kemampuan & Kondisi tempat Tinggal & Nilai Kondisi Tempat Tinggal $(0-10)$ \\
\hline & & Lokasi tempat Tinggal & Nilai Strategis Lokasi tempat tinggal $(0-10)$ \\
\hline & & Jumlah tanggungan & Nilai Maksimal (10 ) / Jumlah Tanggungan \\
\hline & & Nilai Penghasilan & $\begin{array}{l}\text { (Jumlah penghasilan - Jumlah Pengeluaran) } \\
\text { / Jumlah Angsuran }\end{array}$ \\
\hline & & Nilai Rata - Rata Kemampuan & Total Nilai kemampuan / 4 \\
\hline \multirow[t]{5}{*}{5} & Karakter & Prilaku & Nilai Prilaku ( $0-10)$ \\
\hline & & Penampilan & Nilai Penampilan $(0-10)$ \\
\hline & & Interaksi Masyarakat & Nilai Interaksi Masyarakat (1 -10) \\
\hline & & Ketaatan Beribadah & Nilai ketaatan Beribadah $(1-10)$ \\
\hline & & Nilai Rata - Rata Karakter & Total Nilai Karakter / 4 \\
\hline
\end{tabular}

Setelah Nilai dari setiap kriteria didapatkan maka masuk pada tahap Fuzzifikasi. Pada tahap ini, nilai yang dihasilkan adalah derajat keanggotaan dari tiap kriteria. Representasi dari variabel input pada sistem ini tersaji pada Gambar 3.

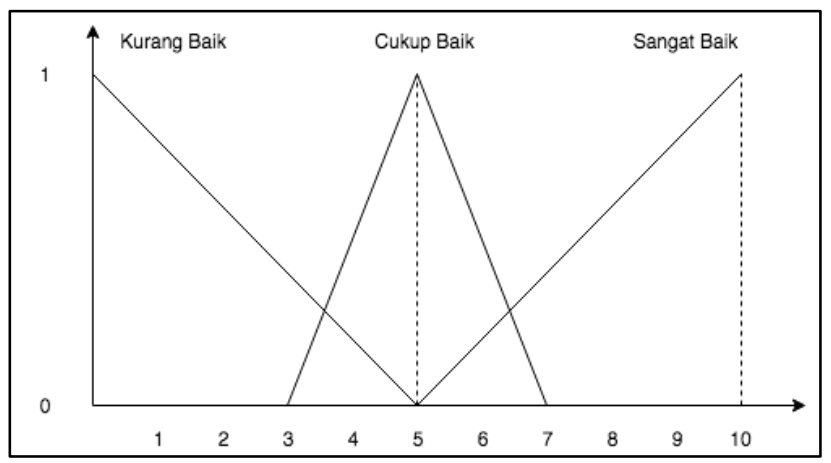

Gambar 3. Fungsi keanggotaan variabel input

Persamaan untuk mencari nilai keanggotaan "Kurang Baik" seperti pada persamaan 1. Sementara itu, untuk mencari nilai keanggotaan "Cukup Baik" digunakan persamaan 2, sedangkan nilai keanggotaan "Sangat Baik" pada persamaan 3.

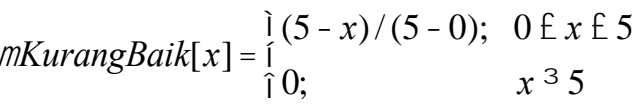

$$
\begin{aligned}
& 0 ; \quad x \quad 3 \text { ataux } 7 \\
& \text { CukupBaik }[x]=\left(\begin{array}{lll}
x & 3
\end{array}\right) /\left(\begin{array}{lllll}
5 & 3
\end{array}\right) ; \quad \begin{array}{lll}
3 & x & 5
\end{array}
\end{aligned}
$$

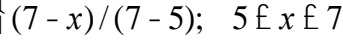

$$
\begin{aligned}
& 0 ; \quad x \quad 5 \\
& \text { SangatBaik }[x]=\left(\begin{array}{ll}
x & 5
\end{array}\right) /\left(\begin{array}{lllll}
10 & 5
\end{array}\right) ; \quad 5 \quad x \quad 10 \\
& 1 ; \quad x \quad 10
\end{aligned}
$$

Setiap nilai kriteria diidentifikasi sesuai dengan representasi pada Gambar 3, kemudian nilai dimasukkan ke dalam persamaan 1, persamaan 2 atau persamaan 3, disesuaikan dengan fungsi keanggotaannya.

Inferensi yang digunakan dalam penelitian ini adalah Metode Tsukamoto. Inferensi ini berbasis kaidah (rule). Rule yang digunakan pada penelitian ini sebanyak 81 aturan seperti pada Tabel II.

TABEL II

RULE PENENTUAN TINGKAT KELAYAKAN PINJAMAN

\begin{tabular}{crrrrl}
\hline No & Karakter & Jaminan & Kemampuan & Usaha & \multicolumn{1}{c}{ Kelayakan Pinjaman } \\
\hline $\mathbf{1}$ & Sangat Baik & Sangat Baik & Sangat Baik & Sangat Baik & Sangat Layak \\
$\mathbf{2}$ & Sangat Baik & Sangat Baik & Sangat Baik & Cukup Baik & Sangat Layak \\
$\mathbf{3}$ & Sangat Baik & Sangat Baik & Sangat Baik & Kurang Baik & Layak Resiko Rendah \\
$\mathbf{4}$ & Sangat Baik & Sangat Baik & Cukup Baik & Sangat Baik & Sangat Layak \\
$\mathbf{5}$ & Sangat Baik & Sangat Baik & Cukup Baik & Cukup Baik & Layak Resiko Rendah \\
$\mathbf{6}$ & Sangat Baik & Sangat Baik & Cukup Baik & Kurang Baik & Layak Resiko Tinggi \\
$\mathbf{7}$ & Sangat Baik & Sangat Baik & Kurang Baik & Sangat Baik & Layak Resiko Rendah \\
$\mathbf{8}$ & Sangat Baik & Sangat Baik & Kurang Baik & Cukup Baik & Layak Resiko Tinggi \\
\hline
\end{tabular}




\begin{tabular}{cccccl}
\hline 9 & Sangat Baik & Sangat Baik & Kurang Baik & Cukup Baik & Layak Resiko Tinggi \\
$\mathbf{1 0}$ & Sangat Baik & Cukup Baik & Sangat Baik & Cukup Baik & Layak Resiko Rendah \\
· & & & & & \\
· & & & & & \\
$\mathbf{8 1}$ & Kurang Baik & Kurang Baik & Kurang Baik & Kurang Baik & Tidak Layak \\
\hline
\end{tabular}

Tahap inferensi dilanjutkan dengan melakukan pemilihan aturan yang sesuai berdasarkan nilai kriteria karena tidak semua aturan pada Tabel 2 digunakan untuk setiap perhitungan. Selanjutnya dilakukan pencarian nilai $\alpha$-predikat dengan menggunakan metode Min, kemudian ditentukan nilai $\mathrm{z}$ untuk setiap aturan yang digunakan dengan menggunakan fungsi keanggotaan kelayakan pinjaman. Fungsi keanggotaan kelayakan pinjaman ditunjukkan pada Gambar 4.

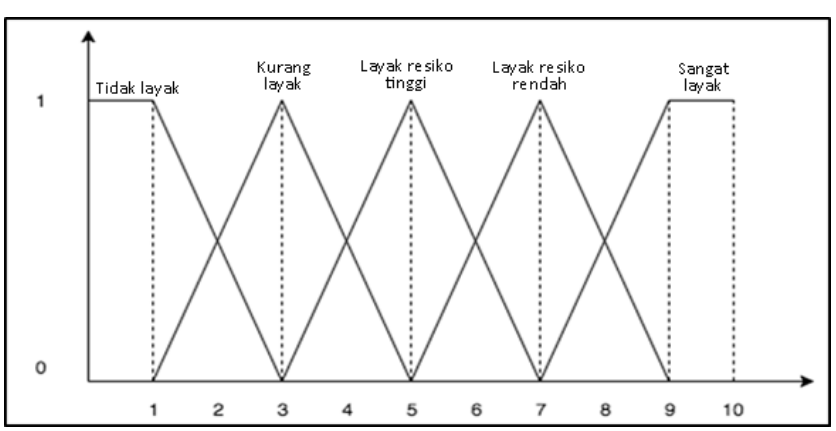

Gambar 4. Fungsi keanggotaan kelayakan pinjaman

Untuk menentukan nilai-nilai keanggotaan "Tidak layak", "Kurang layak", "Layak resiko tinggi", "Layak resiko rendah", dan "Sangat layak" masing-masing digunakan persamaan 4 s.d. persamaan 8 .

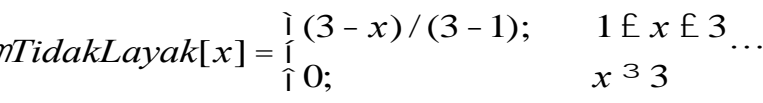

$$
\begin{aligned}
& 0 ; \quad x \text { 1ataux } 5
\end{aligned}
$$

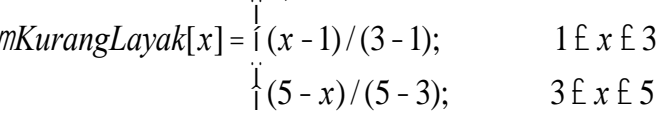

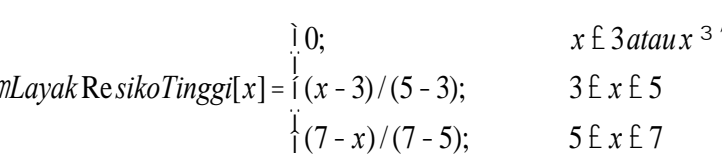

$$
\begin{aligned}
& 0 ; \quad x \quad 5 \text { ataux } 9 \\
& \text { Layak Resiko Rendah }[x]=\left(\begin{array}{lllll}
x & 5
\end{array}\right) /\left(\begin{array}{llll}
7 & 5
\end{array}\right) ; \quad \begin{array}{llll}
5 & x & 7
\end{array} \\
& \left(\begin{array}{ll}
9 & x
\end{array}\right) /\left(\begin{array}{ll}
9 & 7
\end{array}\right) ; \quad 7 \quad x \quad 9
\end{aligned}
$$

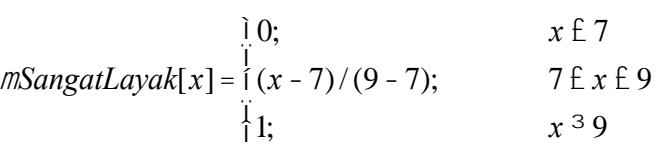

Langkah selanjutnya adalah defuzzikikasi menggunakan persamaan 9. Hasil defuzzifikasi berupa nilai $\mathrm{Z}$ yang merupakan nilai akhir yang digunakan untuk menentukan predikat kelayakan pada proses penilaian pinjaman. Output/keluaran sistem berupa derajat keanggotaan pada himpunan penilaian kelayakan.

$$
Z=\frac{\text { pred }_{1} z_{1}+\text { pred }_{2} z_{2} \ldots \ldots \ldots \ldots \ldots+\text { pred }_{n} z_{n}}{\text { pred }_{1}+\text { pred }_{2}+\ldots \ldots \ldots \ldots \ldots \ldots \text { pred }_{n}}
$$

\section{B. Hasil Aplikasi}

Saat menjalankan sistem penilaian kelayakan pinjaman, halaman yang pertama kali tampil adalah halaman Login. Untuk melanjutkan proses penilaian maka Admin harus melakukan proses Login terlebih dahulu untuk melakukan validasi Username dan Password. Tampilan halaman Login ditunjukkan pada Gambar 5.

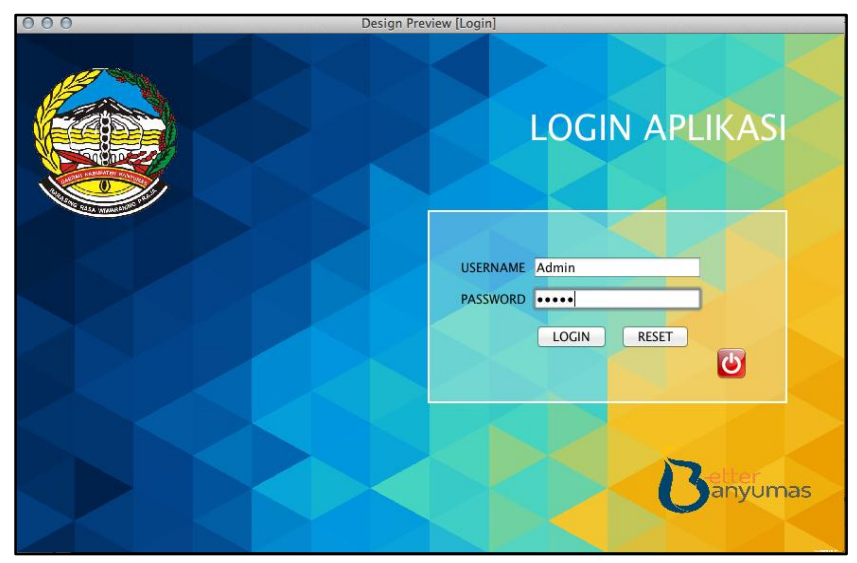

Gambar 5. Tampilan halaman Login

Setelah berhasil melakukan proses login maka sistem akan menampilkan halaman utama. Pada halaman utama terdapat beberapa menu di antaranya menu pemohon, menu analis, menu Rule, menu peminjam dan menu penilaian. Tampilan halaman menu utama dapat dilihat pada Gambar 6. 


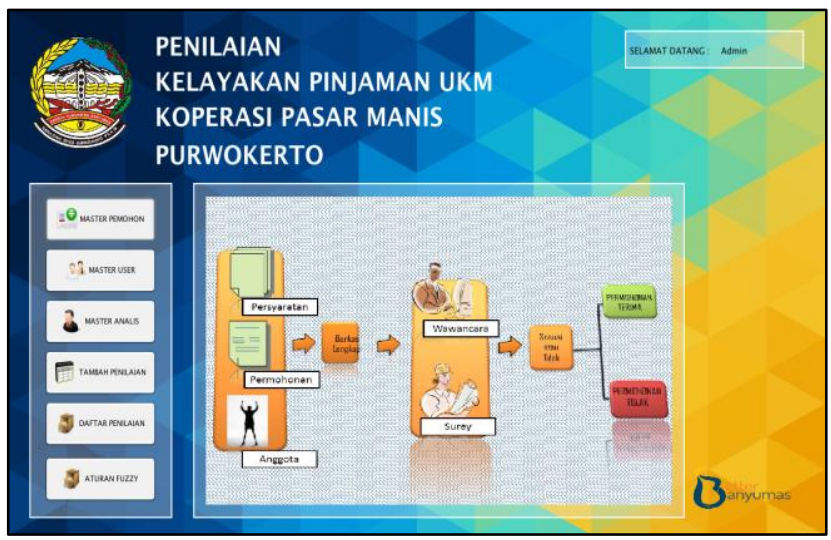

Gambar 6. Tampilan halaman utama

Untuk melanjutkan proses penilaian maka Admin harus masuk ke dalam menu pemohon guna menyimpan data pemohon yang akan diproses. Setelah data pemohon tersimpan maka Admin masuk ke dalam menu penilaian yang terdapat pada halaman utama. Tampilan pada halaman penilaian dapat dilihat pada Gambar 7.

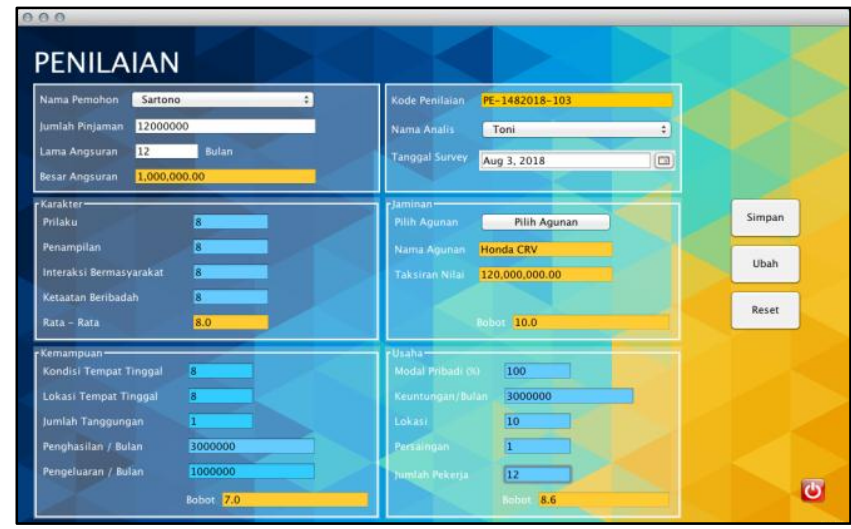

Gambar 7. Tampilan halaman penilaian

Proses penilaian dilanjutkan mengisi semua field. Setelah semua field terisi tersimpan, sistem akan menampilkan hasil dari penilaian yang dapat dilihat pada halaman hasil penilaian. Tampilan dari halaman hasil penilaian dapat dilihat di Gambar 8.

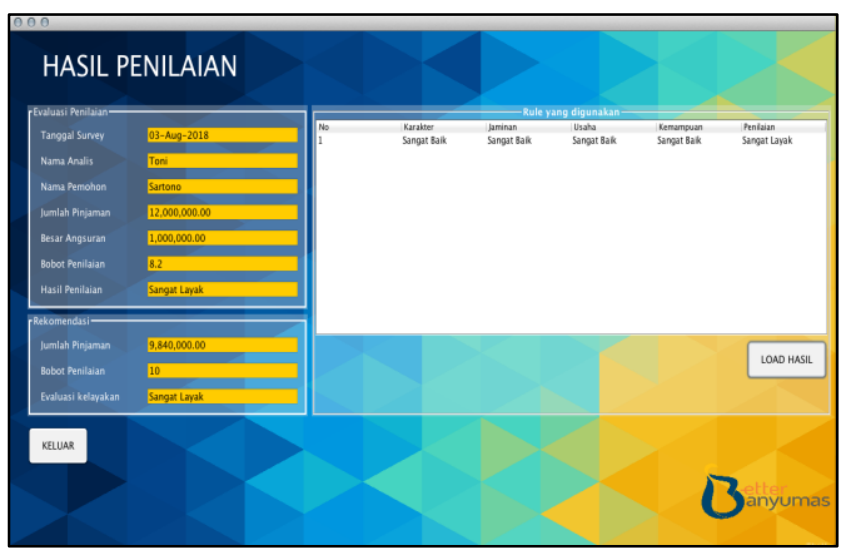

Gambar 8. Tampilan halaman hasil penilaian
Berdasarkan contoh masukan pada Gambar 7, jika pemohon memiliki kriteria rata-rata nilai karakter adalah 8.0, kemampuan dengan bobot 7.0, nilai jaminan 10.0, dan usaha dengan bobot 8.6, maka hasil penilaian sebagaimana pada Gambar 8 adalah "Sangat layak". Hal ini didasarkan atas nilai masing-masing kriteria terhadap derajat keanggotaan pada masing-masing himpunan fuzzy yang terdapat pada Rule-1 sebagai berikut:

1) Derajat keanggotaan karakter $=8.0$ adalah 0.6 pada himpunan sangat baik

2) Derajat keanggotaan kemampuan $=7.0$ adalah 0.4 pada himpunan sangat baik

3) Derajat keanggotaan jaminan $=10.0$ adalah 1 pada himpunan sangat baik

4) Derajat keanggotaan usaha $=8.6$ adalah 0.72 pada himpunan sangat baik

sehingga diperoleh nilai $\alpha$-predikat $=0.4$ berdasarkan Rule-1. Dengan nilai $\alpha$-predikat ini dilanjutkan penghitungan nilai $\mathrm{z}_{1}$ sebagai rata-rata terbobot dan dihasilkan $\mathrm{z}_{1}=7.8$. Nilai $\mathrm{z}_{1}$ ini memiliki dua keanggotaan himpunan penilaian sebagaimana dalam Gambar 4 yaitu "Sangat layak" dan "Layak resiko rendah". Oleh karena itu, dihitung nilai keanggotaan dari masing-masing himpunan dan diperoleh $\mu$ Sangatlayak[7.8] $=0.4$ dan $\mu$ Layakresikorendah[7.8] $=0.6$. Nilai dari $\operatorname{MIN}(\mu$ Sangatlayak[7.8]; $\mu$ Layakresikorendah[7.8]) = 0.4. Hasil akhir diperoleh kesimpulan bahwa pemohon dinyatakan $40 \%$ sangat layak untuk diberikan pinjaman.

\section{PENUTUP}

Berdasarkan penelitian yang sudah dilakukan dapat diambil kesimpulan bahwa inferensi fuzzy metode Tsukamoto dapat digunakan sebagai salah metode membangun aplikasi berbasis logika fuzzy untuk membantu dalam melakukan penilaian terhadap kelayakan calon penerima pinjaman di Koperasi Pasar Manis Sejahtera Purwokerto. Sebagai pengembangan dari sistem ini, dapat dilakukan penambahan kriteria penilaian dan melakukan penambahan modul angsuran yang nantinya dapat dijadikan kriteria dalam evaluasi penilaian kelayakan pinjaman.

\section{DAFTAR PUSTAKA}

[1] H. Mustafidah, Konsep Dasar Logika Fuzzy dan Contoh Aplikasinya, I. Yogyakarta: UMPPress - Pustaka Pelajar, 2013. 
[2] D. Asset, "Credit Risk Assessment by Means of Fuzzy Logic Prediction," J. Multidiscip. Eng. Sci. Technol., vol. 2, no. 5, pp. 902-904, 2015.

[3] N. Ramadan and A. S. Abdelghany, "A Fuzzy Logic Model for Credit Risk Rating of Eqyptian Commercial Banks," Int. J. Comput. Sci. Inf. Secur., vol. 14, no. 2, pp. 11-18, 2016.

[4] D. K. Malhotra and R. Malhotra, "Evaluating Loans Using a Combination of Data Envelopment and NeuroFuzzy Systems," Syst. Cybernatics Informatics J., vol. 13, no. 1, pp. 67-77, 2015.

[5] N. R. Gilke, S. S. Mantha, and G. T. Thampi, "Fuzzy Logic based Decision Support System for Mass Customization," Int. J. Comput. Appl., vol. 62, no. 7, pp. 31-37, 2013.

[6] H. Mustafidah and D. Aryanto, "Sistem Inferensi Fuzzy untuk Memprediksi Prestasi Belajar Mahasiswa Berdasarkan Nilai Ujian Nasional, Tes Potensi Akademik, dan Motivasi Belajar," JUITA (Jurnal Inform., vol. II, no. 1, pp. 1-7, 2012.

[7] H. Mustafidah and S. Suwarsito, "Sistem Inferensi Fuzzy untuk Memprediksi Tingkat Kelulusan Mahasiswa Berdasarkan Motivasi dan Minat Belajar, Kompetensi dan Kehadiran Dosen dalam Perkuliahan," in Prosiding Konferensi Nasional Ilmu Komputer (KONIK) 2014, 2014, pp. 22-28.
[8] T. Pinandita, A. Ahmad, and M. Hindayati, "Sistem Inferensi Fuzzy Tsukamoto untuk Menentukan Tingkat Kompetensi Pedagogik," in Prosiding Seminar Nasional Informatika (SNIF) dan Call for Paper STMIK Potensi Utama Medan dalam rangka Rakornas APTIKOM 2012, 2012, pp. 432-436.

[9] T. Pinandita, A. Ahmad, and H. Mustafidah, "Penentuan Tingkat Kompetensi Sosial Guru Menggunakan Sistem Inferensi Fuzzy," in Prosiding SENAIK APTIKOM 2013, 2013, pp. 544-548.

[10] S. Suwarsito and H. Mustafidah, "Pengembangan Sistem Korelasional Tingkat Kompetensi Dosen terhadap Tingkat Kelulusan Mahasiswa Menggunakan Sistem Inferensi Fuzzy," JUITA (Jurnal Inform., vol. III, no. 1, pp. 1-9, 2014.

[11] H. Rahmadi, Martono Akbar Mustafidah, "Sistem Inferensi Fuzzy untuk Mengetahui Pengaruh Motivasi Belajar dan Lingkungan Belajar terhadap Prestasi Belajar Mahasiswa," JUITA (Jurnal Inform., vol. III, no. 1, pp. 19-24, 2014.

[12] D. Y. Liang, Introduction to Java Programming, 10th ed. New Jersey: Pearson Education Inc., 2016.

[13] K. E. Kendall and J. E. Kendall, Systems Analysis and Design, 7th ed. New Jersey: Pearson Prentice Hall, 2008.

[14] Kasmir, Manajemen Perbankan, 1st ed. Jakarta: Raja Grafindo Persada, 2012. 